\title{
Maternal and neonatal complications in mothers aged under 18 years
}

\author{
This article was published in the following Dove Press journal: \\ Patient Preference and Adherence \\ 30 June 2010 \\ Number of times this article has been viewed
}

\author{
Naiyereh Najati' \\ Morteza Gojazadeh ${ }^{2}$ \\ 'Departments of Neonatology and \\ ${ }^{2}$ Physiology, Faculty of Medicine, Tabriz \\ University of Medical Sciences, Iran
}

Objective: The aim of this study was to evaluate maternal and neonatal complications in mothers delivering babies when aged younger than 18 years.

Methods: In this retrospective study, all labors attended during a one-year period at Alzahra Referral Hospital were evaluated for level of risk. We recorded maternal risk factors, including age, type of delivery, health status, and other factors including marital status and familial marriage. Neonates were evaluated according to prematurity, birth weight, and general health status.

Results: There were 186 mothers under the age of 18 years, comprising $2.6 \%$ of all deliveries at our institution. We divided them in two groups according to age, ie, Group 1 (under 15 years) and Group 2 (15-18 years). Rates of normal vaginal delivery and cesarean section were $83 \%$ and $17 \%$, respectively. The prevalence of eclampsia and pre-eclampsia in Group 1 was twice that in Group 2. Rates of still birth, prematurity, low birth weight and very low birth weight were higher in Group 1 than in Group 2 (9.09\%, 18.1\%, 16.7\%, and 4.5\% versus 4.6\%, 13.9\%, 13.6\%, and $1.9 \%$, respectively). The rate of familial marriage was $18 \%$, and $16 \%$ of the offspring of these marriages were complicated by congenital malformations and still birth. These complications were twice as common in Group 1 compared with Group 2 (11\% versus 5\%, respectively).

Conclusion: Maternal age under 18 years is a risk factor for complications in both mothers and neonates, and even more so in mothers aged younger than 15 years.

Keywords: neonate, adolescent mothers, complications

\section{Introduction}

Teenage pregnancy is an important public health problem, especially in developing countries, with a high rate of marriages at a young age, along with poor prenatal and postnatal care. There were 17,000,000 babies born to teenage mothers in 1997 worldwide, of which 16,000,000 occurred in developing countries. In these countries, $15 \%-20 \%$ of all deliveries were in mothers aged younger than 19 years, and $25 \%$ of maternal deaths occurred in this age group. ${ }^{1}$ Teenage mothers are also at high risk of malnutrition and sexually transmitted diseases. Medical complications in this age group during pregnancy include anemia, urinary tract infection, hypertension, pre-eclampsia, eclampsia, and a high rate of instrument delivery and cesarean section.

Miller et al reported that the rate of very low birth weight (VLBW) infants delivered to women aged under 18 years is twice that of all women of reproductive age. ${ }^{2}$ Stain et al evaluated the complications of pregnancy in 16,500 women and reported that the rate of premature delivery in 11-15-year-old mothers is higher than that for 16-19-year-old mothers of comparable socioeconomic status. ${ }^{3}$ Amini et al have reported
Correspondence: Naiyereh Najati Department of Neonatology, Children General Hospital, Sheshglan Street, PO Box 57367, Tabriz, Iran Tel + I I 984 II 5262250

Fax +II 98 4II 5262290

Email n.najati@yahoo.co.uk 
similar results. The neonates of teenage mothers are also at high risk for prematurity, low birth weight (LBW), still birth, and perinatal death. ${ }^{4}$

Teenage mothers in developing countries at increased risk for anemia, preterm labor, and cesarean section. Cunningham et al reported that pregnancy complications are responsible for the deaths of more than 70,000 young mothers in the world annually, and one million of their babies die before their first birthday. ${ }^{5}$ Nevertheless, the actual role of maternal age in these statistics is not well understood. The purpose of this study was to determine whether teenage pregnancy is associated with adverse outcomes in a developing country setting, where the majority of pregnant women are at risk of malnutrition and poor prenatal care.

\section{Materials and methods}

This hospital-based retrospective study was conducted in the Obstetric and Gynecology Department of Alzahra Hospital, a tertiary teaching institution affiliated with the Tabriz University of Medical Sciences. The study was approved by the University Review Board, and informed consent was obtained from all patients or their guardians.

All mothers aged under 18 years who delivered between July, 012006 and June, 302007 at Alzahra Hospital were included in this study. Data were collected on maternal age, marital status, type of delivery, maternal health (including pre-eclampsia, eclampsia, and anemia) and neonatal status (including birth weight, gestational age, gender, health status, and congenital anomalies). Women who had had previous multiple pregnancies and those expecting multiple births, as well as those with serious comorbidity, were excluded. We defined prematurity as duration of pregnancy less than 37 weeks, LBW as $<2500 \mathrm{~g}$, very low birth weight VLBW as $<1500 \mathrm{~g}$, and maternal anemia as a hemoglobin level $<12 \mathrm{~g} / \mathrm{dL}$ and hematocrit $<37$. All neonates underwent a thorough physical examination to rule out major and minor congenital malformations.

\section{Comparative groups}

Mothers were divided in two groups, ie, under 15 years (Group 1) and 15-18 years (Group 2). The two groups were comparable for socioeconomic status and standard of prenatal care.

\section{Statistical analysis}

Data for continuous variables were presented as mean \pm standard deviation, and comparisons were done using the independent samples $t$-test. The relationships between quantitative variables were tested by chi-square test or Fisher's exact test. $P$ values less than 0.05 were considered statistically significant. Analyses were performed by SPSS software (version 15.0; SPSS Inc., Chicago, IL).

\section{Results}

In the 12-month period from July 01, 2006 to June 30, 2007, 186 women aged under 18 years underwent high-risk delivery at the Alzahra Referral Hospital. Nine of these women were excluded due to high gravidity, three because of multiple pregnancy, and another for concomitant malignancy. The remaining 173 cases were included. Twentytwo cases (13\%) were in Group 1 and 151 cases (87\%) were in Group 2. Overall, 144 women (83\%) had a normal vaginal delivery along with episiotomy, and 29 cases (17\%) had a cesarean section. There were no instrumental deliveries. There were three cesarean deliveries (13.6\%) in Group 1 and $26(17 \%)$ in Group $2(P=0.004)$. The overall incidence of cesarean section was $17 \%$.

The frequency of pre-eclampsia and eclampsia was twice as high in Group 1 compared with Group $2(n=1[4 \%]$ and $\mathrm{n}=3[2 \%$, respectively, $P=0.001)$. The rate of still birth was significantly higher in Group 1 than in Group $2(9.9 \%$ versus $4.6 \%, P=0.031$ ).

Overall, $27 \%$ of mothers were anemic, and 48 mothers aged under 18 years had some degree of anemia. The frequency of anemia in Group 1 was $50 \%$ and in Group was $24.5 \%(P=0.039)$. The rate of prematurity was $18.1 \%$ in Group 1 and $13.9 \%$ in Group $2(P=0.23)$. There were 29 LBW infants (16.7\%) in Group 1 and $13.6 \%$ in Group 2 $(P=0.11)$, and four VLBW neonates $(4.5 \%)$ in Group 1 and $1.9 \%$ in Group $2(P=0.03$, see Table 1$)$.

There were two unmarried teenage mothers $(1.15 \%)$ in the total sample. Thirty-one women $(18 \%)$ were in familial marriages, resulting in still birth in $16 \%$ of cases, with one case of anencephaly. We did not find any remarkable results related to neonatal gender.

Table I Relationship between maternal age and neonatal complications

\begin{tabular}{lllll}
\hline Maternal group & \multicolumn{4}{l}{ Neonatal complication } \\
\cline { 2 - 5 } & LBW & VLBW & Still birth & Preterm \\
\hline Group I* & $16.7 \%$ & $4.5 \%$ & $9.09 \%$ & $18.1 \%$ \\
Group 2** & $13.6 \%$ & $1.09 \%$ & $4.6 \%$ & $13.9 \%$ \\
P value & 0.23 & 0.03 & 0.031 & 0.023 \\
\hline
\end{tabular}

Abbreviations: LBW, low birth weight; VLBW, very low birth weight. 


\section{Discussion}

Teenager mothers pose a challenge in obstetric medicine. Reported rates of pregnancy in women aged under 18 years vary from $3.2 \%-42 \%$. According to the 2006 census for East Azarbayjan, North Western Province, Iran, teenage girls comprised $17 \%$ of the population in this area. Therefore, their general health, marital, and child-bearing status is an important issue. In our study, the proportion of mothers aged under 18 years being referred to our institution for high-risk pregnancy was $2.5 \%$.

Fraster et al suggested that young age is a potential risk factor in pregnancy. ${ }^{6}$ Stain concluded that pregnancy in 16-19-year-old women is more safe than in those aged under 15 years. ${ }^{3}$ Amini et al reported similar findings. ${ }^{4} \mathrm{We}$ investigated our young mothers for maternal complications, including pre-eclampsia, eclampsia, anemia, and type of delivery.

In our study, the rate of cesarean section was $13.6 \%$ in Group 1 and $17.2 \%$ in Group 2. This discrepancy is probably due to the LBW and VLBW births in Group 1. Claire reported a $16 \%$ rate of cesarean section, and Aguslin suggested a rate of $14 \% .^{7}$ Indications for cesarean section in our study were fetal bradycardia, cephalopelvic disproportion, pre-eclampsia, premature rupture of membranes, and breech presentation. The second problem was anemia. We found a $27 \%$ rate of anemia in our young mothers overall, with the rate being twice as high in Group 1 (50\%) compared with Group $2(25 \%, P=0.31) .^{7}$ This is very different from the rate of anemia of $6 \%$ reported by Claire et al who defined anemia as a hemoglobin level $<10 \mathrm{~g} / \mathrm{dL}$, whereas we defined it as $<12 \mathrm{~g} / \mathrm{dL}$.

The frequency of pregnancy-induced hypertension (pre-eclampsia and eclampsia) was proportionately twice as high in Group 1 compared with Group 2. The overall rate of pre-eclampsia and eclampsia was $2.3 \%$, which is similar to the rate of $1.9 \%$ reported by Claire et al. ${ }^{7}$ In a study by Agustin et al the frequency of pre-eclampsia in mothers under 19 years was $1.1 \%$, which is again similar to our results. ${ }^{1}$

We had a $9.9 \%$ still birth rate in Group 1 versus $4.6 \%$ in Group 2. There is a meaningful correlation between pregnancy in women aged under 15 years and stillbirth $(P=18 \%)$. In similar studies, the rate of stillbirth was $1.3 \%$ in De Vienne et al. This is different with our findings because they included mothers aged 14-30 years in their study. ${ }^{7}$ However, in the study by Agustin et al the rate of still birth was $1.4 \%$ in women aged $15-19$ years. ${ }^{1}$ In our study, $18.1 \%$ of neonates in Group 1 and $13.9 \%$ of those in Group 2 were born prematurely. Another study by Agustin et al showed the rate of prematurity as being $1.08 \%$ in mothers aged younger than 19 years. ${ }^{1}$ This compares with a prematurity rate of $8.1 \%$ reported by Claire et al in mothers aged $14-30$ years. ${ }^{7}$ Overall, $16.7 \%$ of the neonates in this study were LBW infants (17.4\% in the Group 1 and $13.6 \%$ in Group 2), which compares with rates of $8.9 \%$ reported by Claire et al for 14-30-year-old mothers and $10.5 \%$ by Siddharthix Yadev in 15-19-year-old mothers. ${ }^{8}$ The frequency of VLBW neonates was $2.3 \%$ overall in our study ( $4.5 \%$ in Group 1 and 1.9\% in Group 2), ie, 4.5 times more common in Group 1 than in Group 2. This compares well with the 1.4\% rate of VLBW infants in the study by Agustin et al. ${ }^{1}$

Only two mothers $(1.15 \%)$ in our study were unmarried, and delivered LBW neonates, one of which was preterm and complicated with oligohydramnios. De Vienare reported an ummarried prevalence rate of $12.6 \%$ in a similar study. Consanguinity in our study was $18 \%$, with $16 \%$ of births in this group complicated by still birth, anencephaly, and other congenital abnormalities. In one Saudi Arabian study, the rate of consanguinity was $29.8 \%{ }^{9}$

\section{Conclusion}

This study shows that teenager mothers are at higher risk of pre-eclampsia, eclampsia, and anemia, and their offspring are at higher risk of still birth, prematurity, LBW, and VLBW. The younger the mother, the higher the rate of maternal and neonatal complications. Adequate prenatal care of the adolescent mother is essential for reducing the risk of obstetric complications in this age group.

\section{Acknowledgments}

The authors would like to thank the Vice Chancellor for Research at Tabriz University of Medical Sciences for providing funds for this study. We also thank Dr Cambiz Pouryousof for his contribution to this research.

\section{Disclosure}

The authors report no conflict of interest in this work.

\section{References}

1. Conde-Agudelo A, Belizan JM. Maternal-perinatal morbidity and mortality associated with adolescent pregnancy in Latin America: Cross-sectional study. Am J Obstet Gynecol. 2005;192:342-349.

2. Miller HS, Lesser KB, Reed KL. Adolescence and very low birth weight infants: A disproportionate association. Obstet Gynecol. 1996;87: 83-88.

3. Satin AJ, Leveno KJ, Sherman ML, et al. Maternal youth and pregnancy outcomes: Middle school versus high school age group compared with women beyond the teen years. Am J Obstet Gynecol. 1994;171: 184-187. 
4. Amini SB, Catalano PM, Dierker LJ, Mann LI. Births to teenagers: Trends and obstetric outcomes. Obstet Gynecol. 1996;87(5 Pt 1):668-674.

5. Cunningham FG, MacDonald PC, Gant NF, Leveno KJ, Glistrap LC. The morphological and functional development of the fetus. In: Cunningham FG, editor. Williams Obstetrics. 20th ed. Stamford, CT: Appleton and Lange; 1997.

6. Fraser AM, Brockert JE, Ward RH. Assocation of young maternal age with adverse reproductive outcomes. Obstet Gynecol. 1995;87 (5 Pt 1):668-674.
7. De Vienne CM, Creveuil C, Drefus M. Does young maternal age increase the risk of adverse obstetric, fetal and neonatal outcomes: A cohort study. Eur J Obstet Gynecol Reprod Biol. 2009;147:151-156.

8. Yadav S, Choudhary D, Mandal RK, et al. Adverse reproductive outcomes associated with teenage pregnancy. Mcgill J Med. 2008;11: $141-144$.

9. Shawky S, Milaat W. Cumulative impact of early maternal marital age during the child bearing. Pediatr Perinatal Epidemiol. 2001;15: $27-33$.

\section{Publish your work in this journal}

Patient Preference and Adherence is an international, peer-reviewed, open access journal that focusing on the growing importance of patient preference and adherence throughout the therapeutic continuum. Patient satisfaction, acceptability, quality of life, compliance, persistence and their role in developing new therapeutic modalities and compounds to optimize clinical outcomes for existing disease states are major areas of interest. This journal has been accepted for indexing on PubMed Central. The manuscript management system is completely online and includes a very quick and fair peer-review system. Visit http://www.dovepress.com/ testimonials.php to read real quotes from published authors. 